\title{
Tomographic behavior of pneumonia caused by SARS-CoV-2
}

Luis A. Concha-Rebollar, ${ }^{1 *}$ Eva A. Izquierdo-Echávarri, ${ }^{1}$ Luis F. Alva-López, ${ }^{1}$

Francisco J. Ayala-Ochoa ${ }^{1}$ and Vito S. Hernández-Melchor ${ }^{2}$

'Imaging Department, Hospital Médica Sur; ${ }^{2}$ Physiology Department, Faculty of Medicine, Universidad Nacional Autónoma de México. Mexico City, Mexico

\begin{abstract}
Background: From the first report of the respiratory disease caused by SARS-Cov-2 towards the end of 2019, in Wuhan, China, to June 8, 2020, 6,931,000 people had been affected in the world, and 113,619 in Mexico, where there is a lack of literature describing the tomographic behavior of this disease throughout its evolution and its correlation with patient clinical data. Objective: To identify, describe and classify the manifestations detected on chest computed tomography images of patients with pneumonia caused by SARS-CoV-2. Method: Hospitalized patients with RT-PCR-confirmed SARS-CoV-2 infection and who underwent a plain chest tomography were included. Results: The most common tomographic patterns were ground glass opacity, consolidation, cobblestone pattern and mixed pattern, with peripheral and subpleural distribution and bilateral involvement in up to $95 \%$. Subpleural bands that distorted the architecture were identified in up to $62 \%$ of patients, with an average of seven days of evolution. The most common extrapulmonary finding was an increase in pulmonary artery transverse axis. Conclusion: Knowing the behavior of this type of pneumonia allows becoming familiarized with the characteristic tomographic patterns, in order to aid timely detection and treatment.
\end{abstract}

KEY WORDS: Pneumonia caused by coronavirus. Covid-19. SARS-CoV-2. Tomographic findings.

\section{Comportamiento tomográfico de la neumonía causada por SARS-CoV-2}

\section{Resumen}

Introducción: Desde el primer reporte de la enfermedad respiratoria causada por SARS-Cov-2 a finales de 2019, en Wuhan, China, hasta el 8 de junio de 2020, habían sido afectadas 6931000 personas en el mundo y 113619 en México, donde se carece de informes que describan el comportamiento tomográfico de esta enfermedad a lo largo de su evolución y su correlación con los datos clínicos del paciente. Objetivo: Identificar, describir y clasificar las manifestaciones en las imágenes de tomografía de tórax de pacientes con neumonía causada por SARS-CoV-2. Método: Se incluyeron pacientes hospitalizados con infección por SARS-CoV-2 confirmada mediante PCR-TR y en quienes se realizó tomografía simple de tórax. Resultados: Los patrones tomográficos más comunes fueron opacidad de vidrio despulido, consolidación, empedrado y patrón mixto, con distribución periférica, subpleural y afectación bilateral hasta en $95 \%$. Se identificaron bandas subpleurales que distorsionaban la arquitectura hasta en $62 \%$ de los pacientes, con un promedio de siete días de evolución. El aumento del eje transverso de la arteria pulmonar constituyó el hallazgo extrapulmonar más frecuente. Conclusión: Conocer el comportamiento de este tipo de neumonía permite la familiarización con los patrones tomográficos característicos, con el fin de coadyuvar a la detección y tratamiento oportunos.

PALABRAS CLAVE: Neumonía causada por coronavirus. Covid-19. SARS-CoV-2. Hallazgos por tomografía.

Correspondence:

*Luis A. Concha-Rebollar

E-mail: lacr03@ hotmail.com
Date of reception: 09-06-2020

Date of acceptance: $27-07-2020$

DOI: 10.24875 /GMM.M20000426
Gac Med Mex. 2020;156:390-396

Contents available at PubMed

www.gacetamedicademexico.com

0016-3813/С 2020 Academia Nacional de Medicina de México, A.C.. Published by Permanyer. This is an open access article under the CC BY-NC-ND license (http://creativecommons.org/licenses/by-nc-nd/4.0/). 


\section{Introduction}

Towards the end of 2019, an outbreak of an unknown viral disease was identified in Wuhan, Hubei, China; on February 11, 2020, the International Taxonomy Committee designated the responsible virus as SARS-CoV-2, based on established phylogeny, taxonomy and practice. Shortly after, the World Health Organization named this disease COVID-19. ${ }^{1}$ The virus spread rapidly outside of China, with a series of cases being confirmed in different countries. By June 9, 2020, a total of 113,619 confirmed cases and 13,511 deaths had been recorded in Mexico. ${ }^{2}$

Pneumonia caused by SARS-CoV-2 has nonspecific and diverse characteristics on chest computed tomography (CT) images. Typical findings on chest CT include ground glass opacity, which is usually bilateral and multifocal, irregular consolidations of peripheral and subpleural distribution, with a predilection towards the posterior segments and lower lobes. Ground glass opacity is increased attenuation that is observed in a variety of interstitial and alveolar processes, with bronchial and vascular margins preservation; in turn, consolidation is an opacification area that darkens the margins of the vessels and the walls of the respiratory tract. $^{3}$

\section{Objective}

The purpose of this study is to describe the lesions observed on chest CT images obtained in 112 patients with pneumonia caused by SARS-CoV-2 who were admitted to the Médica Sur hospital in Mexico City, and to correlate the findings with the time of disease evolution and patient clinical characteristics. Knowing the behavior of this type of pneumonia allows radiologists and other physicians in related areas to become familiar with the characteristic tomographic patterns, in order to aid timely detection and treatment, as well as to reduce the risk of future transmission.

\section{Method}

This retrospective study was approved by the Médica Sur research ethics committee. Patients admitted between March 21 an April 30, 2020, were selected. Hospitalized patients with a RT-PCR-confirmed (nasopharyngeal smear) SARS-CoV-2 diagnosis, who underwent a simple chest tomography scan were included. Information on clinical data was obtained from the electronic medical record. Of 112 recruited patients, 82 were men and 30 were women.

\section{Image acquisition}

On patient admission to the emergency department, simple chest CT scans were performed with a 128-channel multidetector scanner. The detailed parameters for $\mathrm{CT}$ acquisition were the following: Tube voltage, $120 \mathrm{kV}$; standard tube current, $159 \mathrm{mAs}$; 2.0-mm section thickness; and $1.0-\mathrm{mm}$ reconstruction interval. The exploration range was from the pulmonary apex to the diaphragm in the axial plane. All images were obtained with the patient in the supine position and maximal inspiration.

\section{Image analysis}

All CT images were stored and independently reviewed by a radiologist on duty, a radiologist in training, and two radiologists assigned to the imaging area (with vast experience in chest imaging); the images were evaluated at workstations of the PACS system, using a window for the mediastinum and the lung. The chest CT findings were classified according to the Fleischner Society Glossary. The following patterns were taken into account: ground glass opacities, consolidation, "crazy-paving" (cobblestone) and mixed.

The CT images were classified according to the evolution stage ${ }^{4}$ as determined according to the number of days referred by the patient from the onset of symptoms to emergency department admission. Radio-opacities were considered according to their location, involvement by lobe and appearance or distribution. An assessment was carried out using a severity scale, and other associated findings were described (adenomegalies, pulmonary artery transversal diameter increase and pleural effusion).

\section{Statistical analysis}

Categorical data are shown as percentages, whereas numerical data are expressed as means \pm standard deviation. To evaluate whether the populations of men and women came from a sample with normal statistical behavior, the D'Agostino-Pearson test was used. For the comparison between men and women, the chi-square test was used for categorical data, and Student's t-test for numerical data. Data with $p$-values 
$<0.05,<0.01$ or $<0.001$ were regarded as significant. Pearson's correlation coefficient was used to evaluate the correlation between continuous numerical variables. The Venn sets graphic representation to describe the tomographic patterns was carried out using the https://bioinfogp.cnb.csic.es/tools/venny/index. $\mathrm{html}$ page. The analyses were carried out with the Prism 7.0 software.

\section{Results}

The population was normally distributed by gender according to the D'Agostino-Pearson test; 82 men $(73.2 \%)$ and 30 women $(26.8 \%)$ were identified. Mean age was significantly higher in women (56 \pm 3.2 years) than in men $(49 \pm 1.6$ years, $p<0.05)$, and it ranged from 19 and 85 years in men and from 26 to 81 years in women, whereas the median was 46 years in men and 58 in women. The most prevalent risk factors were hypertension and diabetes, with no significant differences being observed between men and women (Table 1). All patients presented with clinical symptoms upon admission, with the most common being fever, cough and dyspnea (Table 2).

\section{Tomographic characteristics}

On the plain chest CT scan carried out at each patient's admission, the most common patterns were the following: predominantly peripheral and subpleural ground glass opacity (Fig. 1), which was found in $15.9 \%$ of men and $20 \%$ of women; consolidation, with predominance towards the postero-basal segments (Fig. 2); as well as the crazy-paving and mixed patterns, with the latter being a concomitant form of the above patterns (Fig. 3). The percentages of the different pattern combinations are depicted on the Venn diagrams (Fig. 4).

In $5 \%$ of the patients, involvement was unilateral, and in the rest, bilateral, with involvement of two or more lobes, with lesions subpleural and peripheral distribution (Table 3). A finding that stood out was the presence of subpleural bands that distorted the pulmonary structure (Fig. 5), which were found in 70 patients $(62 \%)$ who had an average disease evolution of seven days since the first day of symptom onset. According to their number, the presence of bands was assessed as mild, moderate and severe with a visual and subjective scale. The most common associated extrapulmonary finding (12 patients, $10 \%$ ) was an increase in the pulmonary artery transverse axis,
Table 1. Risk factors by gender in patients with pneumonia caused by SARS-CoV-2

\begin{tabular}{|l|c|c|c|c|}
\hline Risk factors & Total (\%) & Men (\%) & Women (\%) & $\chi^{2}$ \\
\hline Hypertension & 17.9 & 15.9 & 23.3 & NS \\
\hline Diabetes & 16.1 & 14.6 & 20.0 & NS \\
\hline Heart disease & 4.5 & 2.4 & 10.0 & NS \\
\hline Dyslipidemia & 3.6 & 2.4 & 6.7 & NS \\
\hline Neoplasm & 1.8 & 2.4 & 0.0 & NS \\
\hline Smoking & 0.9 & 1.2 & 0.0 & NS \\
\hline
\end{tabular}

NS = non-significant

Table 2. Most common symptoms in patients with pneumonia caused by SARS-CoV-2

\begin{tabular}{|l|c|c|c|c|}
\hline Symptoms & Total (\%) & Men (\%) & Women (\%) & $\chi^{2}$ \\
\hline Fever & 83.0 & 87.8 & 70.0 & 0.03 \\
\hline Cough & 71.4 & 70.7 & 73.3 & NS \\
\hline Dyspnea & 67.9 & 65.9 & 73.3 & NS \\
\hline Malaise & 58.0 & 63.4 & 43.3 & 0.06 \\
\hline Headache & 47.3 & 54.9 & 26.7 & 0.01 \\
\hline Rhinorrhea & 25.0 & 24.4 & 26.7 & NS \\
\hline Diarrhea & 16.1 & 11.0 & 30.0 & 0.02 \\
\hline Pharyngodynia & 14.3 & 14.6 & 13.3 & NS \\
\hline Somnolence & 10.7 & 7.3 & 20.0 & 0.05 \\
\hline
\end{tabular}

NS = non-significant.

measured at the level of the bifurcation in the transverse plane (taking a $29-\mathrm{mm}$ size as reference). ${ }^{5}$ The results are described in table 4.

Patients were classified according to the stages indicated by Pan et al. (2020): 4

- Early stage (zero to four days after initial symptom), at which 28 patients were found. The ground glass pattern was identified in $68 \%$ of patients, consolidation pattern in $43 \%$ and crazy-paving pattern in $25 \%$, as well as mild subpleural bands in $32 \%$ (Table 4).

- Progressive stage (five to eight days after initial symptom), at which 51 patients were found. Consolidation pattern was observed in $69 \%$, ground glass in $67 \%$ and crazy-paving pattern in $39 \%$. Mild subpleural bands were identified in $45 \%$ and moderate and severe forms in $20 \%$ and $4 \%$, respectively. 

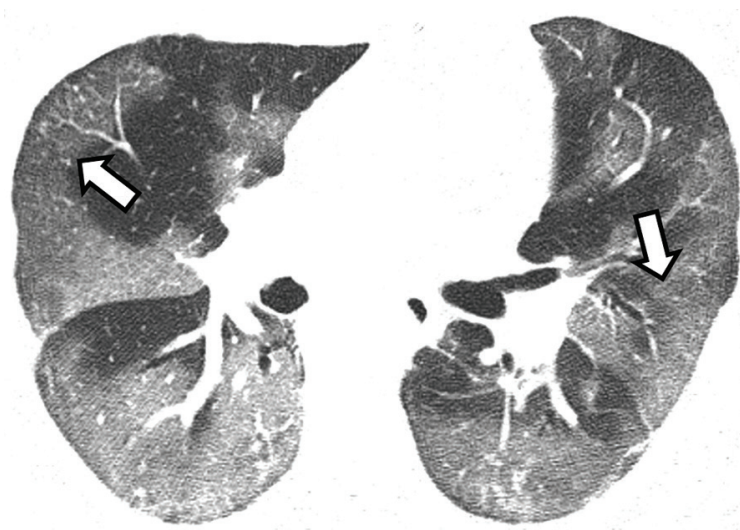

Figure 1. Eighty-three-year-old male patient with pneumonia caused by SARS-CoV-2 of two days' evolution. Ground glass pattern is observed with peripheral predominance (long arrow).

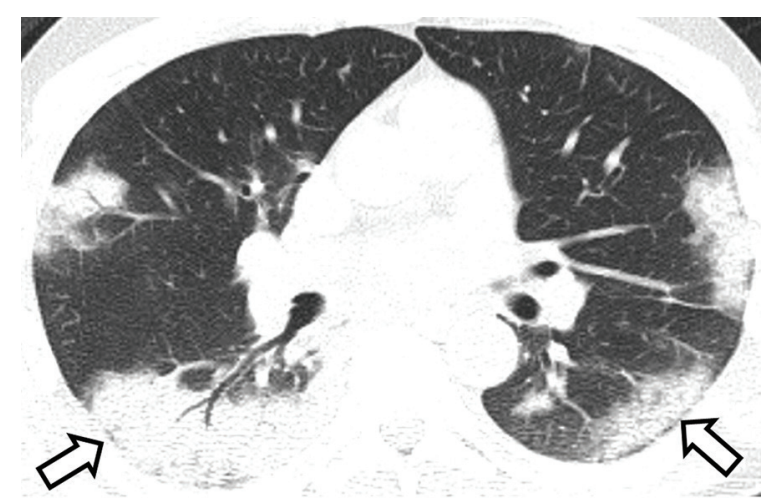

Table 2. Forty-seven-year-old male patient with pneumonia caused by SARS-CoV-2. Consolidations with predominance in postero-basal segments are bilaterally observed (arrow).

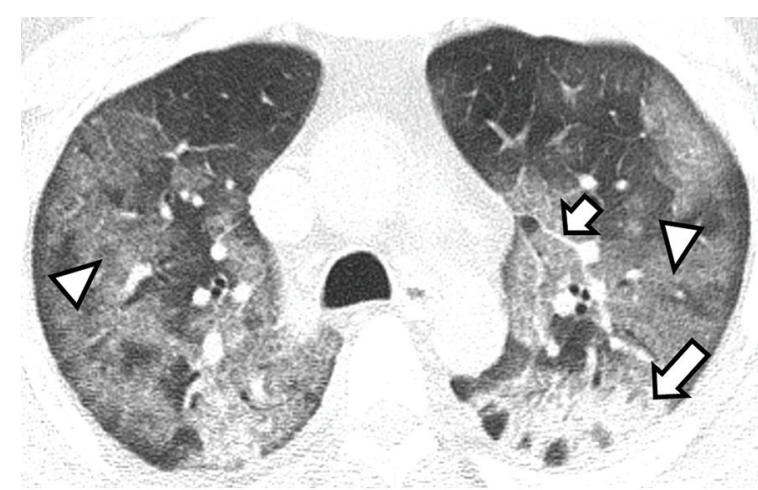

Figure 3. Forty-five-year-old man with pneumonia caused by SARSCoV-2, in whom mixed tomographic pattern is observed. Dense consolidations in posterior segments (long arrow), associated with discrete ground glass (arrowhead) and crazy-paving patterns (short arrow) are appreciated.

- Peak stage (nine to 13 days after initial symptom), at which 19 patients were found. Ground glass, consolidation and crazy-paving patterns were
Table 3. Tomographic patterns frequency, distribution, location, involvement by lobes and associated findings in patients with pneumonia caused by SARS-CoV-2

\begin{tabular}{|c|c|c|c|}
\hline Variables & $\begin{array}{c}\text { Total } \\
(\%)\end{array}$ & $\begin{array}{l}\text { Men } \\
(\%)\end{array}$ & $\begin{array}{c}\text { Women } \\
(\%)\end{array}$ \\
\hline $\begin{array}{l}\text { Patterns } \\
\text { Ground glass opacity } \\
\text { Crazy-paving } \\
\text { Consolidation }\end{array}$ & $\begin{array}{l}69.6 \\
32.1 \\
61.6\end{array}$ & $\begin{array}{l}69.5 \\
30.5 \\
59.8\end{array}$ & $\begin{array}{l}70.0 \\
36.7 \\
66.7\end{array}$ \\
\hline $\begin{array}{l}\text { Subpleural bands } \\
\text { Mild } \\
\text { Moderate } \\
\text { Severe }\end{array}$ & $\begin{array}{c}42.0 \\
17.9 \\
2.7\end{array}$ & $\begin{array}{c}37.8 \\
19.5 \\
3.7\end{array}$ & $\begin{array}{c}53.3 \\
13.3 \\
0.0\end{array}$ \\
\hline $\begin{array}{l}\text { Distribution } \\
\text { Subpleural } \\
\text { Peripheral peribronchial } \\
\text { Patches } \\
\text { Central peribronchovascular }\end{array}$ & $\begin{array}{c}68 \\
52 \\
32 \\
7\end{array}$ & $\begin{array}{c}67 \\
51 \\
32 \\
4\end{array}$ & $\begin{array}{l}70 \\
53 \\
33 \\
17\end{array}$ \\
\hline $\begin{array}{l}\text { Location } \\
\text { Unilateral } \\
\text { Bilateral }\end{array}$ & $\begin{array}{c}5 \\
95\end{array}$ & $\begin{array}{c}6 \\
94\end{array}$ & $\begin{array}{c}3 \\
97\end{array}$ \\
\hline $\begin{array}{l}\text { Involvement by lobes } \\
\text { All } \\
\text { Inferior } \\
\text { Superior } \\
\text { Lingula/middle lobe }\end{array}$ & $\begin{array}{l}92 \\
7 \\
4 \\
3\end{array}$ & $\begin{array}{c}93 \\
7 \\
4 \\
4\end{array}$ & $\begin{array}{c}90 \\
7 \\
3 \\
0\end{array}$ \\
\hline $\begin{array}{l}\text { Associated findings } \\
\text { Pulmonary artery transverse diameter } \\
\text { increase } \\
\text { Atelectasis } \\
\text { Adenomegaly } \\
\text { Peribronchial thickening } \\
\text { Pleural effusion }\end{array}$ & $\begin{array}{l}10 \\
3 \\
2 \\
1 \\
0\end{array}$ & $\begin{array}{l}11 \\
1 \\
1 \\
1 \\
0\end{array}$ & $\begin{array}{l}3 \\
7 \\
3 \\
0 \\
0\end{array}$ \\
\hline
\end{tabular}

observed in 79, 68 and $26 \%$, respectively. Mild, moderate and severe subpleural bands were present in 47,26 and $5 \%$, respectively.

- Resolution stage ( $\geq 14$ days after initial symptom), at which 14 patients were found (Table 5). The ground glass pattern $(71 \%)$ was combined with those of consolidation (64\%) and crazy-paving (29\%), forming mixed patterns.

Semi-quantitative and qualitative assessment of the tomographic pattern was carried out in order to establish a severity scale, ${ }^{6,7}$ according to Juárez Hernández et al. suggestions (Instituto Nacional de Enfermedades Respiratorias, article in press, May 2020). This severity scale aims to predict patient prognosis depending on the extent of pulmonary involvement at each lobe, with the predominant pattern subsequently being identified (Table 5). The data obtained with the scale were correlated with oxygen saturation to determine reciprocity (Fig. 6). 

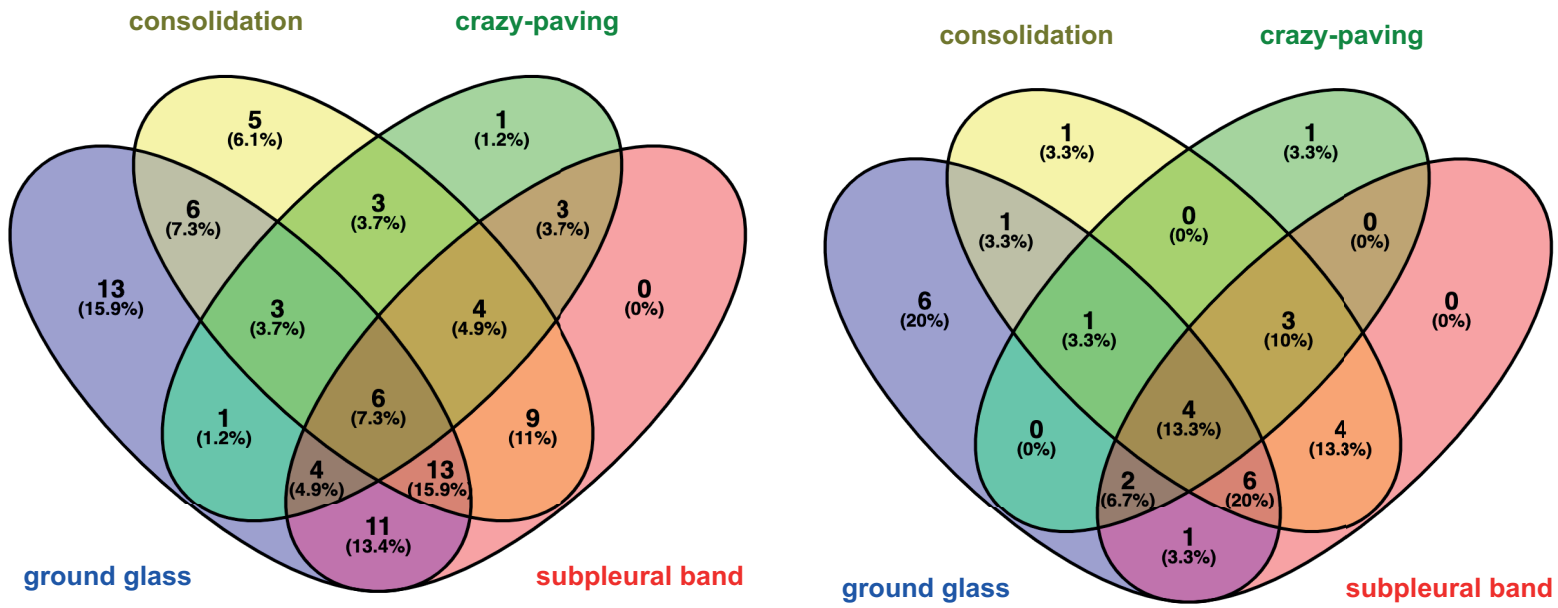

Figure 4. Venn diagram. Tomographic pattern in men (left) and women (right) with pneumonia caused by SARS-CoV-2. The diagram shows the combination of patterns by gender; the number that appears in the sectors of each oval indicates the number of patients who showed the pattern and concomitance with other patterns.

Table 4. Clinical and tomographic characteristics by stages of the disease in patients with pneumonia caused by SARS-CoV-2

\begin{tabular}{|c|c|c|c|c|c|c|c|c|c|c|c|c|}
\hline \multirow[t]{3}{*}{ Variables } & \multicolumn{12}{|c|}{ Stages } \\
\hline & \multicolumn{3}{|c|}{ Early (0-4 days) } & \multicolumn{3}{|c|}{ Progressive (5-8 days) } & \multicolumn{3}{|c|}{ Peak (10-13 days) } & \multicolumn{3}{|c|}{ Resolution (> 14 days) } \\
\hline & Total & M & W & Total & M & W & Total & M & W & Total & M & W \\
\hline \multicolumn{13}{|l|}{ Clinical characteristics } \\
\hline Number of patients & 28 & 22 & 6 & 51 & 38 & 13 & 19 & 15 & 4 & 14 & 7 & 7 \\
\hline Mean age (years) & 48 & 46 & 55.5 & 51.9 & 49.6 & 58.6 & 49 & 48.1 & 52.5 & 52.3 & 53.9 & 50.7 \\
\hline Oxygen saturation (\%) & 92 & 91 & 94 & 87 & 88 & 82 & 85 & 84 & 88 & 84 & 80 & 88 \\
\hline Mean evolution days & 2.9 & 2.9 & 3 & 6.6 & 6.5 & 6.9 & 10.1 & 10.1 & 9.7 & 16.4 & 17.1 & 15.7 \\
\hline Hospitalization days & 7.3 & 8.36 & 3.3 & 11.2 & 9.63 & 15.9 & 5.6 & 6.3 & 2.3 & 9.9 & 12.6 & 7.1 \\
\hline \multicolumn{13}{|l|}{ Tomographic pattern } \\
\hline Ground glass opacity (\%) & 68 & 68 & 67 & 67 & 71 & 54 & 79 & 73 & 100 & 71 & 57 & 86 \\
\hline Crazy-paving (\%) & 25 & 27 & 17 & 39 & 32 & 62 & 26 & 27 & 25 & 29 & 43 & 14 \\
\hline Consolidation (\%) & 43 & 45 & 33 & 69 & 61 & 92 & 68 & 73 & 50 & 64 & 71 & 57 \\
\hline \multicolumn{13}{|l|}{ Subpleural bands } \\
\hline Mild (\%) & 32 & 36 & 17 & 45 & 32 & 85 & 47 & 47 & 50 & 43 & 57 & 29 \\
\hline Moderate (\%) & 4 & 5 & 0 & 20 & 24 & 8 & 26 & 27 & 25 & 29 & 29 & 29 \\
\hline Severe (\%) & 0 & 0 & 0 & 4 & 5 & 0 & 5 & 7 & 0 & 0 & 0 & 0 \\
\hline \multicolumn{13}{|l|}{ Severity index } \\
\hline Extension average score & 11.25 & 11.6 & 10 & 14.1 & 13.9 & 14.7 & 17.1 & 17.9 & 13.3 & 13.5 & 17 & 10.4 \\
\hline
\end{tabular}

\section{Discussion}

The CT scans analyzed in this study were carried out at patient admission; this imaging study, together with clinical predictors of mortality ${ }^{8}$ and oxygen saturation, are parameters that are used for decision-making regarding intubation, hospitalization and patient discharge.
We confirmed that the ground glass pattern with subpleural and peripheral distribution occurred in most cases, and was followed in frequency by the consolidation pattern, with both rarely occurring in isolation, as shown in figure 4 (Venn diagram); the mixed pattern (combination of two or more patterns) was third in frequency. Subpleural bands were observed in numerous patients, which, according to the 
Table 5. Lesion extension semi-quantitative and qualitative evaluation by pulmonary lobes in patients with pneumonia caused by SARS-CoV-2

\begin{tabular}{|c|c|c|}
\hline \multicolumn{3}{|c|}{ Semi-quantitative evaluation } \\
\hline Score & $\begin{array}{l}\text { Involvement } \\
\text { percentage }\end{array}$ & Interpretation \\
\hline 1 & $\leq 5$ & \multirow[t]{2}{*}{ Mild involvement: 1 to 5 points } \\
\hline 2 & $>5-25$ & \\
\hline 3 & $>25-50$ & \multirow{2}{*}{$\begin{array}{l}\text { Moderate involvement: }>5 \text { to } \\
15 \text { points }\end{array}$} \\
\hline 4 & $>50-75$ & \\
\hline 5 & $>75$ & $\begin{array}{l}\text { Severe involvement: > } 15 \text { points } \\
\text { (maximum } 25 \text { points) }\end{array}$ \\
\hline \multicolumn{3}{|c|}{ Qualitative evaluation } \\
\hline Category & $\begin{array}{l}\text { Predominating } \\
\text { pattern }\end{array}$ & Phases of disease \\
\hline A & Ground glass & Initial \\
\hline B & Crazy-paving & Disease progression \\
\hline C & Consolidation & Advanced disease \\
\hline \multicolumn{3}{|c|}{$\begin{array}{l}\text { Severity scale suggested by Juárez Hernández F. et al. (Instituto Nacional de } \\
\text { Enfermedades Respiratorias, article in press, 2020). } \\
\text { Semi-quantitative evaluation: points are assigned to each lobe (five lobes, } 3 \text { right lobes } \\
\text { and } 2 \text { left lobes) according to involvement extent percentage; then, the points are } \\
\text { added and interpreted according to the right column. } \\
\text { Qualitative evaluation: a letter is assigned according to the predominant tomographic } \\
\text { pattern and is interpreted according to the right column. }\end{array}$} \\
\hline
\end{tabular}

literature review, could suggest fibrous bands in formation, which appear after the acute phase of the disease. ${ }^{9}$ We know that pulmonary fibrosis can be a sequel of acute respiratory distress syndrome and, although the virus is eradicated in patients recovered from COVID-19, the development of pulmonary fibrosis is irreversible, which is why there are still speculations about long-term pulmonary consequences of COVID-19, and these should not be assumed without an appropriate prospective study..$^{10}$ Regarding the distribution of lesions, we confirmed bilateral and multifocal lung involvement, which is consistent with the results from previous investigations.

As for the stages of the disease, the following should be mentioned:

- Early stage: the ground glass pattern has been observed as the main finding, with unilateral or bilateral subpleural distribution in the lower lobes. In our study, this presentation coincided; however, we also identified consolidation and crazy-paving patterns, as well as incipient subpleural bands. At this stage, the different patterns can occur independently, which does not occur at subsequent stages.
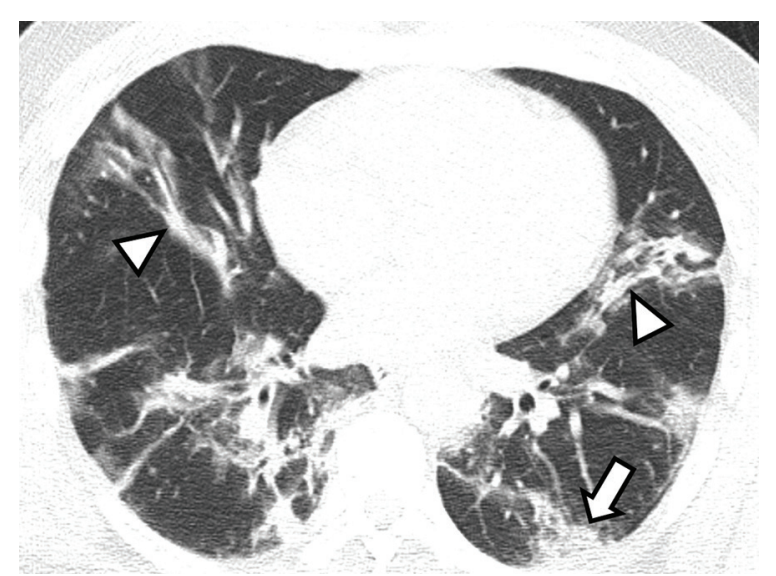

Figure 5. Male patient with pneumonia caused by SARS-CoV-2 of 10 days' evolution, who is at peak stage of the disease. Subpleural bands (arrowhead) associated with dense consolidations (arrow) are observed.

- Progressive stage: according to the literature, it is common to find the ground glass pattern diffusely, and the crazy-paving and consolidation patterns bilaterally. In our study, the consolidation pattern predominated, followed by the ground glass opacity pattern and, finally, by the crazy-paving pattern. From this stage onwards, patients show mixed patterns, and hardly are single patterns observed.

- Peak stage: the most common finding was dense consolidation. In our research, the findings included ground glass opacity, consolidation and crazy-paving patterns, as well as parenchymal bands causing architectural distortion (Fig. 5).

- Resolution stage: it is common to find extensive ground glass pattern as a residual lesion of consolidations. In our study, mixed patterns were found, with subpleural bands as residual lesions of the acute stage.

Our findings are consistent with those reported by Lomoro et al.,"1 who carried out a literature review of approximately 26 articles, 3,886 patients (2,059 men and 1,827 women), with a mean age of 49.39 years. The following findings are indicated in order of frequency: ground glass opacity, consolidation and mixed patterns, with bilateral, peripheral, subpleural and lower lobes' distribution, which is consistent with those observed during our investigation.

The most common extrapulmonary finding was a transverse diameter of the pulmonary artery trunk $>29 \mathrm{~mm}$, which is considered the most specific tomographic sign to diagnose pulmonary hypertension by 


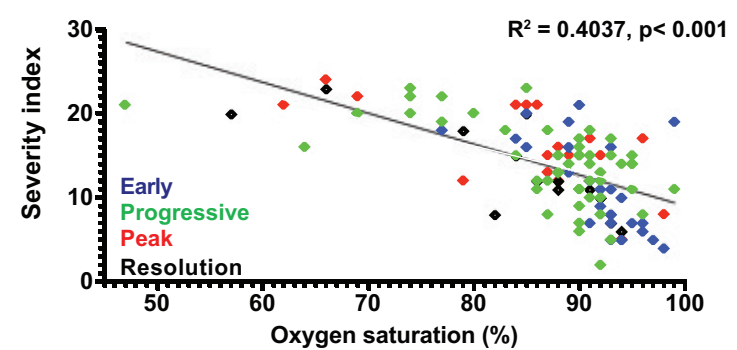

Figure 6. Correlation between the severity index and oxygen saturation according to the stage. There is a relationship between the severity index (by CT scan) and oxygen saturation $\left(r^{2}=0.4037, p<0.001\right)$; however, individual analyses showed that, at early stages (blue), most patients had oxygen saturation $>85 \%$, even when some of them had a high severity index. At other stages, more patients with oxygen saturation $<80 \%$ were observed, and in all of them the severity index was high (> 15 points). A high oxygen saturation does not exclude the possibility of extensive lung damage.

CT scan, and although a lower value does not necessarily exclude this pathology, it has a high positive predictive value of $97 \%$, sensitivity of $87 \%$ and specificity of $89 \%$ for suggesting this pathology. ${ }^{5}$ This finding is not mentioned in other reviews, perhaps due to its subjective nature; however, its etiology could be related to thrombotic processes in COVID-19 pathogenesis. $^{12}$

Regarding the suggested severity scale, it is useful only to guide about the degree of involvement of the lung parenchyma, since it is not in direct relationship with oxygen saturation or with the actual clinical condition of the patient, which confirms the clinical-radiological dissociation referred to in the literature $^{13}$ (Fig. 6).

\section{Conclusion}

We provide the first description of the typical tomographic patterns of pneumonia caused by SARSCoV-2 in Mexican patients, and analyze the frequency they occur with in men and women at different stages of the disease. This will allow clinicians to become familiar with classic CT findings for early detection. In our population, pulmonary artery increased diameter was a common finding that may indicate pulmonary hypertension. We demonstrated that subpleural bands appear after the acute phase of the disease, but a long-term prospective study is required to corroborate if they can cause pulmonary fibrosis. In addition, the pulmonary severity scale suggested by Juárez Hernández et al. was corroborated to not always be correlated with patient clinical status, and it is useful only to provide an idea of the extent of pulmonary involvement and thereby decide patient management.

\section{Conflict of interests}

The authors of this review declare that they have no conflicts of interest.

\section{Funding}

No funding was received to write this article.

\section{Ethical disclosures}

Protection of human and animal subjects. The authors declare that no experiments were performed on humans or animals for this research.

Confidentiality of data. The authors declare that they have followed the protocols of their work center on the publication of patient data.

Right to privacy and informed consent. The authors have obtained informed consent from the patients and/or subjects referred to in the article. This document is in the possession of the corresponding author.

\section{References}

1. Hosseiny M, Kooraki S, Gholamrezanezhad A, Reddy S, Myers L. Radiology perspective of coronavirus disease 2019 (COVID-19): lessons from severe acute respiratory syndrome and Middle East respiratory syndrome. AJR Am Roentgenol. 2020;214:1078-1082.

2. World Health Organization [Internet]. Switzerland: Coronavirus disease (COVID-19) weekly epidemiological update and weekly operational update; 2020.

3. Zu ZY, Jiang MD, Xu PP, Chen W, Ni QQ, Lu GM, et al. Coronavirus disease 2019 (COVID-19): a perspective from China. Radiology. 2020;296:E15-E25.

4. Pan F, Ye T, Ye T, Sun P, Gui S, Liang B, et al. Time course of lung changes at chest CT during recovery from coronavirus disease 2019 (COVID-19). Radiology. 2020;295:715-721.

5. Peña E, Dennie C, Veinot J, Hernández-Muñiz SH. Pulmonary hypertension: how the radiologist can help. Radiographics. 2012;32:9-32.

6. Wang Y, Dong C, Hu Y, Li C, Ren Q, Zhang X, et al. Temporal changes of CT findings in 90 patients with COVID-19 pneumonia: a longitudinal study. Radiology. 2020 Aug;296(2):E55-E64

7. Yuan M, Yin W, Tao Z, Tan W, Hu Y. Association of radiologic findings with mortality of patients infected with 2019 novel coronavirus in Wuhan, China. PLoS One. 2020;15:e0230548.

8. Ruan Q, Yang K, Wang W, Jiang L, Song J. Clinical predictors of mortality due to COVID-19 based on an analysis of data of 150 patients from Wuhan, China. Intensive Care Med. 2020;46:846-848.

9. Smithuis F, Smithuis R. 32 cases of suspected COVID-19. Imaging findings and follow up [Online]. The Netherlands: Radiology Assistant; 2020.

10. Spagnolo P, Balestro E, Aliberti S, Cocconcelli E, Biondini D, Casa G, et al. Pulmonary fibrosis secondary to COVID-19: a call to arms? Lancet Respir Med. 2020;8:750-752.

11. Lomoro P, Verde F, Zerboni F, Simonetti I, Borghi C, Fachinetti C, et al. COVID-19 pneumonia manifestations at the admission on chest ultrasound, radiographs, and CT: single-center study and comprehensive radiologic literature review. Eur J Radiol Open. 2020;7:100231.

12. Bikdeli B, Madhavan MV, Jiménez D, Chuich T, Dreyfus I, Driggin E, et al. COVID-19 and thrombotic or thromboembolic disease: implications for prevention, antithrombotic therapy, and follow-up. J Am Coll Cardiol. 2020.

13. Inui S, Fujikawa A, Jitsu M, Kunishima N, Watanabe S, Suzuki Y, et al. Chest CT findings in cases from the cruise ship "Diamond Princess" with coronavirus disease 2019 (COVID-19). Radiology: Cardiothoracic Imaging. 2020;2:e200110 